\title{
Erratum to: Genetic Variation of Stem Characters in Wheat and Their Relation to Kernel Weight under Drought and Heat Stresses
}

Ahmed Sallam*, Mervat Hashad, El-Sayed Hamed, Mohamed

Erratum to: J. Crop Sci. Biotech. 18(3): 137-146

DOI No. 10.1007/s12892-015-0014-Z

In page 143, in Table 7., the first line of the table

"1000-kernel" should be changed as follows:

"stem"

In page 144, in Table 8., the first line of the table

"1000-kernel" should be changed as follows:

"stem"

We apologize to readers for the mistake.

The online version of the original article can be found at http://link.springer.com/article/10.1007/s12892-015-0014-z

Ahmed Sallam, Mervat Hashad, El-Sayed Hamed, Mohamed

Department of Genetics, Faculty of Agriculture, Assiut University, 71526 - Assiut, Egypt 